\title{
Optimum Design of GA-BF Algorithm Based PID Controller for the Solar System
}

\author{
S. Mallika ${ }^{1}$, R. Saravanakumarf ${ }^{2}$ \\ ${ }^{1}$ Department of Electrical and Electronics Engineering, Sri Sairam Engineering College, Chennai, India \\ ${ }^{2}$ School of Electrical Engineering, VIT University, Vellore, India
}

\begin{tabular}{l}
\hline Article Info \\
\hline Article history: \\
Received Mar 23, 2017 \\
Revised Aug 20, 2017 \\
Accepted Aug 26, 2017 \\
\hline
\end{tabular}

\section{Keyword:}

Bacterial foraging algorithm Boost converter Genetics algorithm PID controller Solar cell

\begin{abstract}
This paper presents a new approach based on the genetic algorithm (GA) and Bacterial Foraging (BF) is used to perform a constrained tuning technique for the PID parameters to optimize the power output of solar panel. A smallsignal model is used to design the controller parameters of the conventional PID controller. The dynamics of the converter is non linear, therefore, it is hard to derive desirable performance. So hybrid algorithm is used to optimize the control parameters of boost converter. In order to obtain the fitness of an individual, Simulink model of the boost converter is designed and the hybrid algorithm is programmed to design the optimal control parameters. It was found that the proposed optimal PID controller parameters adjustment by the GA-BF algorithm is superior to the conventional method. The Matlab/Simulink was used to verify the effectiveness of proposed control method.
\end{abstract}

Copyright (c) 2017 Institute of Advanced Engineering and Science. All rights reserved.

\section{Corresponding Author:}

S. Mallika,

Department of Electrical and Electroncis Engineering,

Sri Sairam Engineering College, Chennai, India.

Email: mallikamals@gmail.com

\section{INTRODUCTION}

The use of energy has become an integral part of our life; its supply should be secure and sustainable. At the same time, it should be economical, environmentally friendly and socially and acceptable. The current trends in energy consumption are neither secure nor sustainable. The rising consumption of fossil fuels, together with increasing greenhouse gas emission, threatens our secure energy supply. The lack of insufficient energy can also hold back the growth of billions of people living in the developing countries, therefore, development of clean, secure, sustainable and affordable energy sources should be our priority in this century.

PV modules still have relatively low conversion efficiency therefore, controlling maximum power point tracking (MPPT) for the solar array is essential in a PV system. The amount of power generated by a PV depends on the operating voltage of the array. A PV's maximum power point (MPP) varies with solar insulation and temperature [1], [2].

A-BF algorithm has emerged as a powerful technique for the solving optimization problems. Genetic Algorithms (GAs) are a stochastic global search method that mimics the process of natural evolution. The Bacterial Foraging Optimization Algorithm (BFOA), as it is called now, is currently gaining popularity in the community of researchers, for its effectiveness in solving certain difficult real world optimization problems. Using GA-BF algorithms to perform the tuning of the controller will result in the optimum controller being evaluated for the system every time.

The research work connects with the implementation of DC to DC converter with voltage lift technique. The green energy from photo voltaic cell was feed to the power converter with suitable pre 
modeled PV array. The dynamic behavioural characteristics of power electronic converters are too much nonlinear due to the nature of switching and varying nature of time.

A GA-BF based hybrid algorithm controlled MPPT for a Boost power electronics converter has been designed. The controller parameters have been optimized using hybrid algorithms. Controller design and simulations in Matlab Sim Power Systems are carried out in this paper. The control system performs poor in characteristics and even it becomes unstable, if improper values of the controller tuning constants are used. So it becomes necessary to tune the controller parameters to achieve good control performance with the proper choice of tuning constants.

The following section 2 formulates the mathematical modeling of a solar system and boost converter. The focus of section 3 is on conventional PID Controller, it's tuning by Ziegler Nichols Method and how it can be applied to boost converter and also a brief review of GA-BF based hybrid algorithm for optimizing PID controller. In section 4, simulation results of the corresponding system are obtained and compared and conclusions are made in section 5

\section{MATHEMATICAL MODELING OF THE SYSTEM}

Genetics Algorithm and Bacterial Foraging Algorithm (GA-BF) is embedded in the feedback compensation circuit design and it is performed in the frequency domain and aided by Bode plots, the design essentially involves positioning of poles and zeros of the selected compensation circuit to compensate the undesirable characteristics of a power stage. The voltage reference Vref signal is generated from the MPPT controller. In the proposed method the boost converter serves the purpose of transferring maximum power from the solar PV module to the load. A dc/dc converter acts as an interface between the load and the PV array [3]-[4]. The entire system configuration is shown in figure.1.

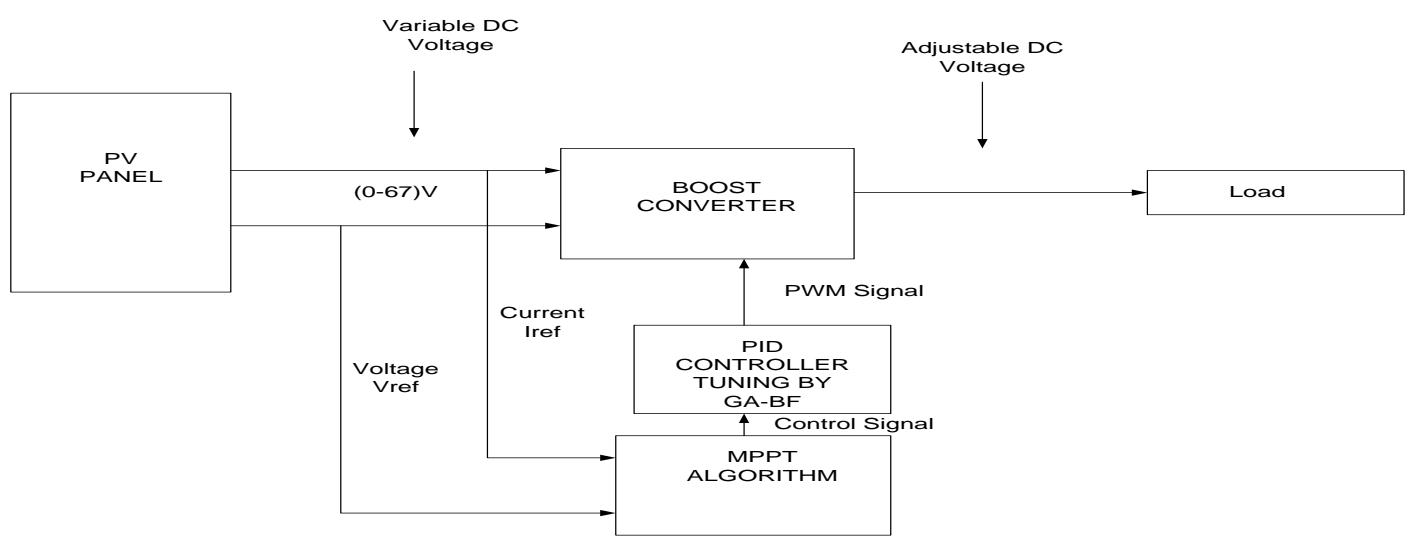

Figure 1. Power Circuit Diagram

\subsection{Solar Cell Modeling}

Solar cell of a given material must be designed to maximize the light to electricity conversion efficiency. An ideal solar cell can be considered as a current source wherein the current produced by the solar cell is proportional to the solar irradiation falling on it. An electrical circuit representing a solar cell is shown in figure.2. The optical loss is represented by the current source itself, where the generated current I is proportional to the light input. The recombination losses are represented by the diode connected parallel to the current source, but in the reverse direction. The ohmic losses in the cell occur due to the series and shunt resistance denoted by Rs and Rsh respectively [5]-[7].

Applying Kirchoff's law to the node where IL, diode, $\mathrm{R}_{\mathrm{sh}}$ and $\mathrm{R}_{\mathrm{s}}$ meet, we get

$$
\mathrm{I}=\mathrm{I}_{\mathrm{L}}-\mathrm{I}_{\mathrm{D}}-\mathrm{I}_{\mathrm{sh}}
$$




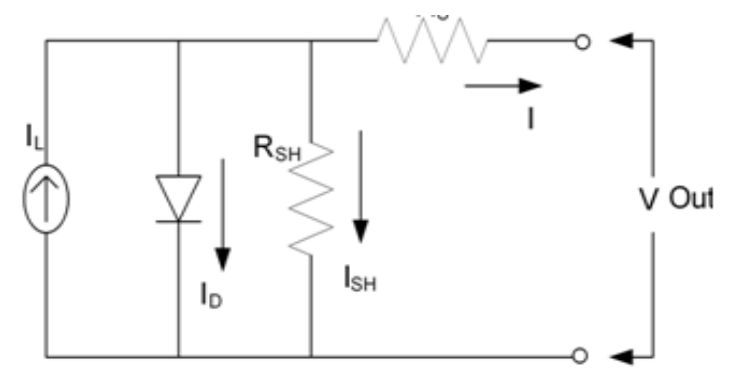

Figure2. Simplified-equivalent Circuit of Photovoltaic Cell

$$
\mathrm{I}=\mathrm{I}_{\mathrm{ph}^{-}} \mathrm{I}_{\mathrm{o}}\left[\exp \left(\frac{V+I R_{S}}{V_{T}}\right)-1\right]-\left[\frac{V+I R_{S}}{R_{p}}\right]
$$

Where, IL is the Insolation current, I is the Cell current, Io is the Reverse saturation current, V is the Cell voltage, Rs is the Series resistance, Rsh is the Parallel resistance, VT is the Thermal voltage (kt/q), K is the Boltzman constant, $\mathrm{T}$ is the Temperature in Kelvin and $\mathrm{q}$ is the Charge of an electron. WAREE WS 100 $\mathrm{PV}$ module is used in this system and its specifications are shown in Table. 1.

\begin{tabular}{cc} 
Table.1 PV Module Specifications of Waree Ws 100 \\
\hline Parameters & Values \\
\hline Maximum Power (Pmax) & $10 \mathrm{~W}$ \\
Voltage at maximum Power (Vmp) & $17 \mathrm{~V}$ \\
Current at max Power (Imp) & $0.59 \mathrm{~A}$ \\
Open Circuit Voltage & $21 \mathrm{~V}$ \\
Short Circuit Current & $0.62 \mathrm{~A}$ \\
Tolerance & $5 \%$ \\
Power Measured at Standard Test & $1000 \mathrm{~W} / \mathrm{m} 2,25 \mathrm{c}, \mathrm{AM}$ \\
Load & 1.5 \\
Temperature Co-efficient of Power & $-0.47 \% \mathrm{I} \mathrm{K}$ \\
Temperature Co-efficient of Voltage & $-0.123 \mathrm{~V} / \mathrm{K}$ \\
Operation Temperature & $-40 \mathrm{C} \mathrm{to} 85 \mathrm{C}$ \\
Nominal operating Cell temp & $48^{\circ} \mathrm{C}$ \\
Maximum System Voltage & $1000 \mathrm{VDC}$ \\
\hline
\end{tabular}

\subsection{Modeling of Boost Converter}

A small-signal model is used to design the controller parameters of the conventional PID controller. The dynamics of the converter is non linear, therefore, it is hard to derive desirable performance. In this paper, GA-BF optimized algorithm is used to control parameters of boost converter [8]-[11].

Boost converters are a kind of high frequency converters which convert unregulated DC power to regulated DC power. Since the output voltage of renewable energy systems is basically unregulated DC voltage, as shown in Figure 3, boost converters are necessary to adjust the DC voltage for different applications and its designed values are given in Table.2.

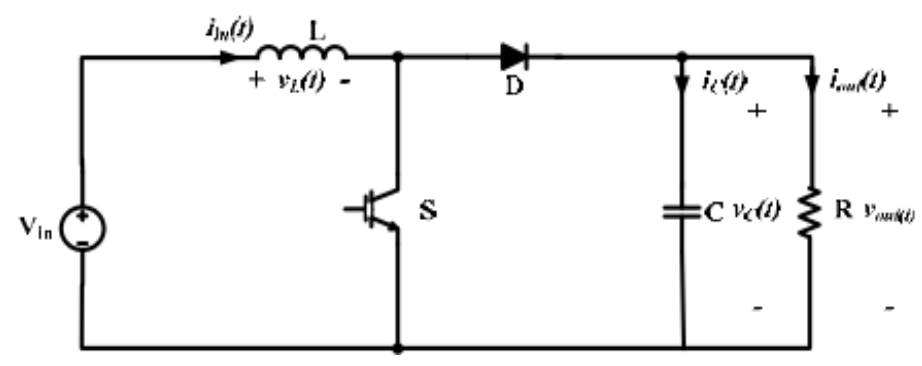

Figure 3. Boost Converter Circuit Diagram 


$$
\text { Load Resistance }=\frac{V_{o}}{I_{O}}
$$

Assuming Io to be $0.4 \mathrm{~A}$.

$$
\text { Duty Cycle }=1-\frac{V_{\text {in }}}{V_{o}}
$$

The desired Capacitance value is

$$
C=\frac{I_{o} \times D}{f_{S} \times \Delta V_{o}}
$$

The Inductance value is choosen by the formula

$$
L=\frac{V_{S} \times D}{f_{S} \times \Delta V_{o}}
$$

The diode loss is calculated by

$$
\text { Diode loss }=V_{d} \times I_{o}(1-D)
$$

The Switching Loss is calculated by

$$
P_{s w}=\left(t_{1}+t_{2}\right) \frac{V_{S} I_{o}}{2} f_{S}
$$

The conversion ratio is given by the following expression:

$$
\frac{V_{o}}{V_{s}}=\frac{I_{s}}{I_{o}}=\frac{1}{1-d}
$$

$\mathrm{d}=\mathrm{T}_{\mathrm{on}} / \mathrm{T}$ where $\mathrm{I}_{\mathrm{s}}$ is the input current of the converter and $\mathrm{T}=\mathrm{T}_{\text {on }}+\mathrm{T}_{\text {off }}$, with its range $1 \geq \mathrm{d} \geq 0$. Knowing the $V_{s}$ and $I_{s}$, we can find the input resistance $R_{\text {in }}$ of the converter. This is given by

$$
R_{\text {in }}=\frac{V_{s}}{I_{s}}=R_{o}(1-d)^{2}
$$

Here, $\mathrm{R}_{\mathrm{in}}$ varies from $\mathrm{R}_{\mathrm{o}}$ to 0 and $\mathrm{d}$ varies from 0 to 1 .

$$
\begin{aligned}
& \left(\left(\begin{array}{l}
\frac{d i_{L}}{d i_{t}} \\
\frac{d v_{C}}{d i_{t}}
\end{array}\right)=\left(\begin{array}{cc}
-R_{O N}+R L+\left(R \times \frac{R_{C}}{\left(R+R_{C}\right)}+\frac{R D}{L}\right. & -\frac{R}{\left(R+R_{C}\right) L} \\
\frac{R}{\left(R+R_{C}\right) C} & \frac{-1}{\left(R+R_{C}\right) V}
\end{array}\right)\left(\begin{array}{l}
i_{L} \\
V_{C}
\end{array}\right)+\left(\begin{array}{l}
\frac{1}{L} \\
0
\end{array}\right) \times V_{\text {in }}\right) \\
& V_{o}=\left(\begin{array}{ll}
R \times \frac{R_{C}}{R+R_{C}} & \frac{R}{R+R_{C}}
\end{array}\right)\left(\begin{array}{l}
i_{L} \\
V_{c}
\end{array}\right)
\end{aligned}
$$

Table 2. Circuit Parameters of the Boost Converter

\begin{tabular}{cc}
\hline Parameter & Value \\
\hline Capacitor & $1056 \mathrm{uf}$ \\
Inductor & $250 \mathrm{uf}$ \\
Load & $25 \mathrm{ohm}$ \\
ESR of & $30 \mathrm{mohm}$ \\
capacitor & \\
ESR of & $10 \mathrm{mohm}$ \\
inductor & \\
\hline
\end{tabular}




\section{OPTIMIZATION TECHNIQUES}

\subsection{Tuning Of PID Controller Using Conventional Approach}

The Ziegler-Nichols tuning method is a heuristic method of tuning a PID controller. It is performed by setting the I (integral) and $\mathrm{D}$ (derivative) gains to zero. Table.3 prescribes the type of controller used for the Ziegler and Nichols method and it is based on the values of $\mathrm{Pu}$ and $\mathrm{Ku}$.

\begin{tabular}{cccc}
\multicolumn{5}{c}{ Table 3. Controller Settings } \\
\hline Controller & $\mathrm{K}_{\mathrm{p}}$ & $\mathrm{T}_{\mathrm{i}}$ & $\mathrm{T}_{\mathrm{d}}$ \\
\hline $\mathrm{P}$ & $\mathrm{K}_{/} / 2$ & & \\
$\mathrm{PI}$ & $\mathrm{K}_{w} / 2.2$ & $\mathrm{P}_{u} / 1.2$ & \\
$\mathrm{PID}$ & $\mathrm{K}_{w} / 1.7$ & $\mathrm{P}_{w} / 2$ & $\mathrm{P}_{w} / 8$ \\
\hline
\end{tabular}

The transfer function of the PID controller is represented by

$$
G c(s)=K p\left(1+\frac{1}{T_{i} s}+T_{d} s\right)
$$

The PID parameters can be calculated as $\mathrm{K}_{\mathrm{p}}=0.05, \mathrm{~K}_{\mathrm{i}}=53$ and $\mathrm{K}_{\mathrm{d}}=0.004675$.

The total response of the system can be calculated as follow

$$
\frac{R(s)}{C(s)}=\frac{0.004675 s^{2}+0.05 s+53}{1953.8112 \times 10^{-12} s^{3}+4.69 \times 10^{-3} s^{2}+0.504675 s+53}
$$

Using the values of the ultimate gain, $\mathrm{Ku}$, and the ultimate period, $\mathrm{Pu}$, Ziegler and Nichols prescribes the following values for $\mathrm{Kc}$, $\mathrm{tI}$ and $\mathrm{tD}$, depending on which type of controller is desired.

\subsection{Tuning Of PID Controller Using GA-BF Algorithm Approach \\ 3.2.1 Continuous Genetics Algorithm}

The genetic algorithm (GA) is an optimization and search technique based on the principles of genetics and natural selection. The continuous $\mathrm{GA}$ also has the advantage of requiring less storage than the binary GA because a single floating-point number represents the variable instead of Nbits integers. The continuous GA is inherently faster than the binary GA, because the chromosomes do not have to be decoded prior to the evaluation of the cost function [12]-[15].

If the chromosome has Nvar variables (an $\mathrm{N}$-dimensional optimization problem) given by $\mathrm{p} 1, \mathrm{p} 2, \ldots$ ., then the chromosome is written as an array with $1 *$ Nvar elements so that Chromosome $=$ $[\mathrm{P} 1, \mathrm{P} 2, \mathrm{P} 3 \ldots . . . \mathrm{PNvar}], \mathrm{Cost}$ function $\mathrm{f}$ at the variables $\mathrm{p} 1, \mathrm{p} 2, \mathrm{p} 3 \ldots \mathrm{pNvar}$.

Cost $=\mathrm{f}($ chromosome $)=\mathrm{f}\left(\mathrm{P} 1, \mathrm{P} 2, \mathrm{P} 3 \ldots . \mathrm{PN} \mathrm{var}_{\mathrm{var}}\right)$

Since $\mathrm{f}$ is a function of $\mathrm{x}$ and $\mathrm{y}$ only, the clear choice for the variable is Chromosome $=[\mathrm{x}, \mathrm{y}]$.

The normalized initial population is

$$
p_{\text {new }}=\beta\left(p_{m n}-p_{d n}\right)+p_{m n}
$$

Variations on this theme include choosing any number of variables to modify and generating different $b$ for each variable.

\subsubsection{Bacterial Foraging Algorithm}

Recently, bacterial foraging algorithm (BFA) has emerged as a powerful technique for the solving optimization problems. BFA mimics the foraging strategy of E. coli bacteria which try to maximize the energy intake per unit time. From the very early days it has drawn attention of researchers due to its effectiveness in the optimization domain. So as to improve its performance, a large number of modifications have already been undertaken. The bacterial foraging system consists of four principal mechanisms, namely 
chemotaxis, swarming, reproduction and elimination-dispersal. A brief description of each of these processes along with the pseudo-code of the complete algorithm is described below. Chemotaxis: This process simulates the movement of an E.coli cell through swimming and tumbling via flagella. Biologically an E.coli bacterium can move in two different ways. It can swim for a period of time in the same direction or it may tumble, and alternate between these two modes of operation for the entire lifetime [16].

\subsubsection{Implementation of GA-BF Based PID Controller}

Hybrid algorithm can be applied to the tuning of PID controller gains to ensure optimal control performance at nominal operating conditions.

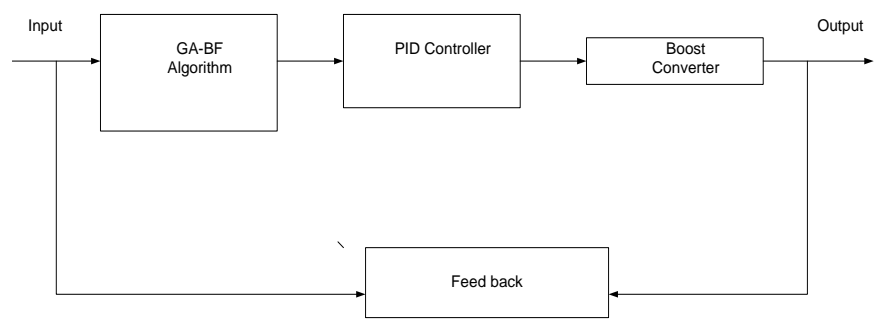

Figure 4. Block Diagram of The Entire System

The block diagram of the entire system is shown in Figure4. The system output is denoted by $R(s)$, its input is denoted by $\mathrm{C}(\mathrm{s})$, and the reference input to the PID controller is denoted by $\mathrm{C}(\mathrm{s})$. GA can be applied to the tuning of PID controller gains to ensure optimal control performance at nominal operating conditions. After giving the above parameters to GA-BF the PID controllers can be easily tuned and thus system performance can be improved. The system performance can be represented by the flow chart shown in Figure 5.

For initialization, the user selects n, S, Sr , Ns, Nc, Nre, Ned, Ped, C1, C2,R1, R2 and c(i), $\mathrm{i}=1,2,3 \ldots \mathrm{S}$. Also initialize the position $\mathrm{Pin}, 1,1,1, \mathrm{i}=1,2,3, \ldots . \mathrm{S}$ and velocity randomly initialized.

Where $\mathrm{n}$ is dimension of search space

$\mathrm{S}$ is the number of bacteria in the population

$\mathrm{Sr}$ is the half of the total bacteria

Ns is the maximum number of swim length $\mathrm{Nc}$ is the number of chemotactic steps

Nre is the number of reproduction steps

Ned is the number of elimination and dispersal steps

Ped is the elimination and dispersal with probability

c(i) is the step size taken in the random direction

$\mathrm{C} 1, \mathrm{C} 2$ are the PSO random parameters and $\mathrm{R} 1, \mathrm{R} 2$ are the PSO random parameters.

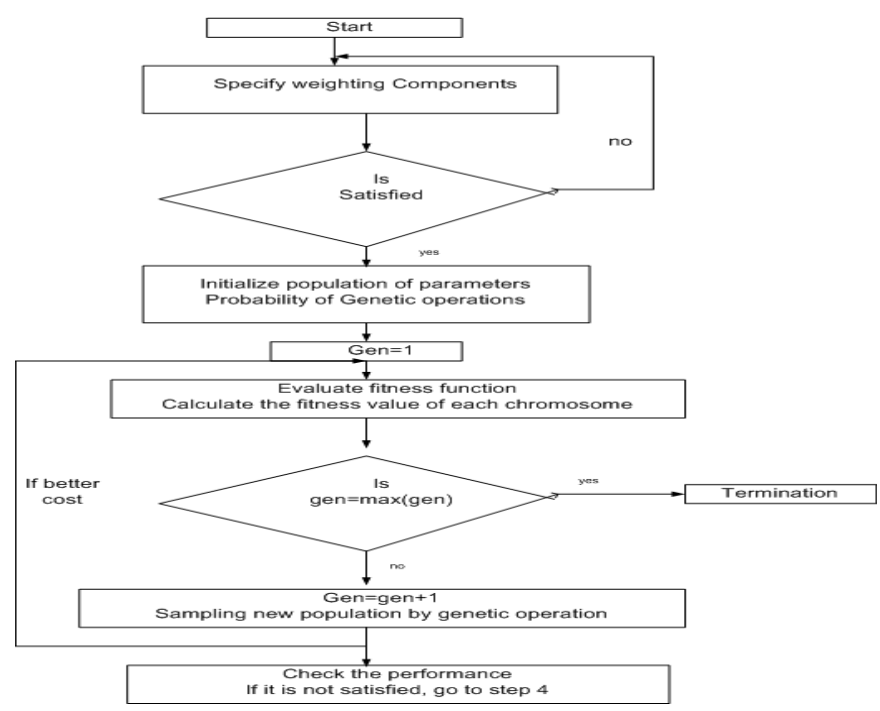


Figure 5. Hybrid Algorithm Architecture

The tuning parameter for the hybrid algorithm is given in Table.4. The overall transfer function of the entire system is

$$
\frac{R(s)}{C(s)}=\frac{K_{d} s^{2}+K_{P} s+K_{i}}{\frac{L C}{(1-d)} s^{2}+\left(K_{d}+\frac{L}{R(1-d)}\right) s^{2}+\left(K_{p}+(1-d)\right) s+K_{i}}
$$

The optimal hybrid algorithm tuned PID parameters can be calculated as $\mathrm{Kp}=0.0233, \mathrm{Ki}=24.6386$ and $\mathrm{Kd}=0.002$. After applying the tuning parameters to the algorithm the PID controllers can be easily tuned and thus system performance can be improved.

$$
\frac{R(s)}{C(s)}=\frac{0.002 s^{2}+0.0233 s+24.6386}{1953.8112 \times 10^{-12} s^{3}+15.314 \times 10^{-6} s^{2}+0.5233 s+24.6386}
$$

Table 4. Tuning Parameters

\begin{tabular}{cc}
\hline GA-BF Property & Value/Method \\
\hline Population Size & 20 \\
Maximum Number of & 30 \\
Generations & E. coli bacteria \\
Bacteria Type & Mean Square Error \\
Performance Index/Fitness & Roulette selection \\
Function & Arithmetic Crossover \\
Selection Method & $75 \%$ \\
Crossover Method & Add/Sub Mutation \\
Crossover Probability & $0.1 \%$ \\
Mutation Method & \\
Mutation Probability &
\end{tabular}

\section{SIMULATION RESULTS}

Recently many variants of hybrid algorithms have been investigated for improving the learning and speed of convergence. The convergence characteristics are shown in Figure 6 and 7. The different bacteria construction is shown in Figure 8 and 9.The step response of the hybrid algorithm is shown in Figure 10. The Table. 5 shows the comparison of different optimization algorithm techniques.

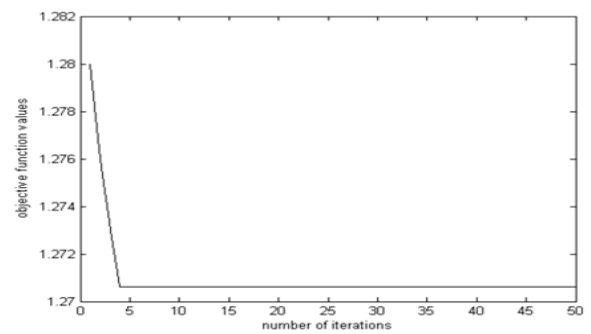

Figure 6. Convergence Characteristics GA-BF

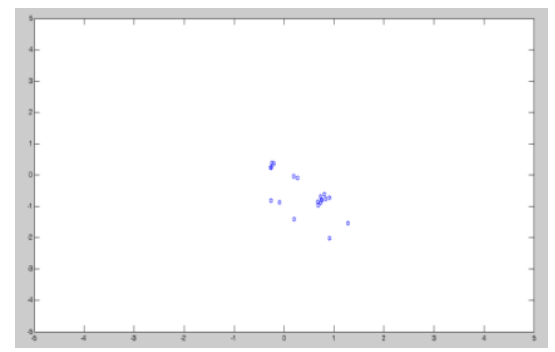

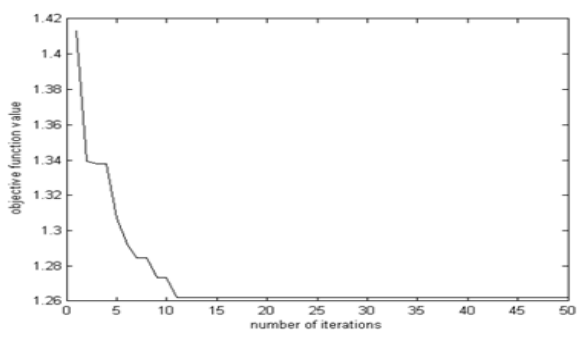

Figure 7. Convergence Characteristics GA-BF

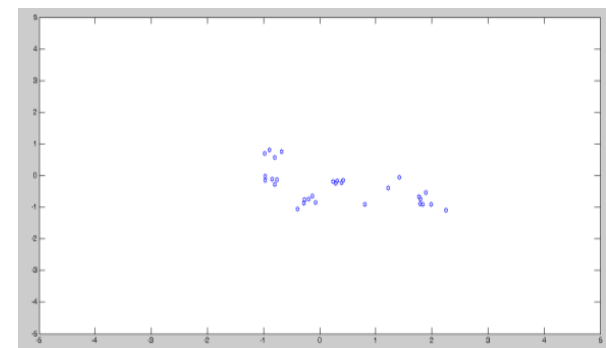


Figure. 8 No of Bacteria considered - 20

Figure 9. No of Bacteria considered - 30

Table. 5 Comparison of Optimization Techniques

\begin{tabular}{ccccc}
\hline $\begin{array}{c}\text { Tuning } \\
\text { Parameters }\end{array}$ & $\begin{array}{c}\mathrm{ZN} \\
\text { Method }\end{array}$ & $\begin{array}{c}\text { Genetic } \\
\text { Algorithm }\end{array}$ & $\begin{array}{c}\text { Bacterial } \\
\text { Foraging } \\
\text { Algorithm }\end{array}$ & $\begin{array}{c}\text { GA-BF } \\
\text { Algorithm }\end{array}$ \\
\hline $\mathrm{Kp}$ & 0.05 & 0.0233 & 0.0211 & 0.0101 \\
$\mathrm{Ki}$ & 53.12 & 24.6386 & 23.54 & 22.56 \\
$\mathrm{Kd}$ & 0.004675 & 0.0020 & 0.0019 & 0.001 \\
Maximum & 0.509 & 0.501 & 0.402 & 0.321 \\
overshoot & & & & 0.0211 \\
Rise time(sec) & 0.0786 & 0.0255 & 0.022 & 0.009 \\
Settling & 0.0963 & 0.0378 & 0.022 & \\
time(Sec) & & & & \\
\hline
\end{tabular}

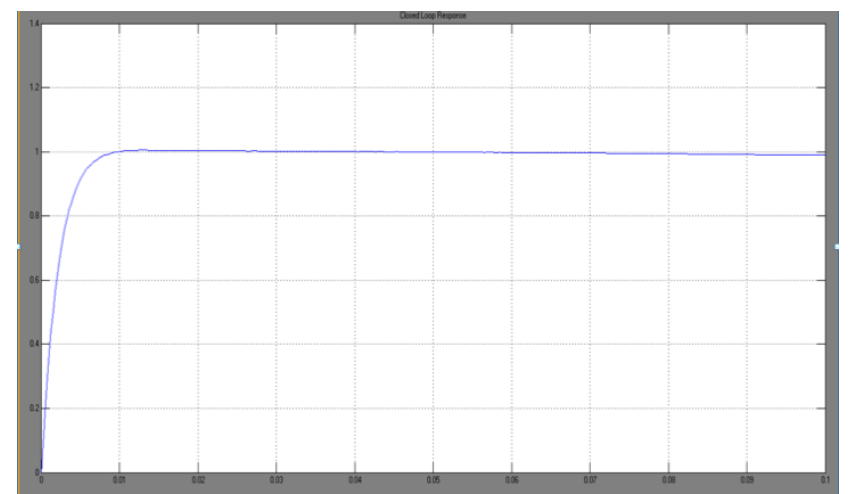

Figure 10. Hybrid Algorithm Step Response.

\section{CONCLUSIONS}

Simulation results emphasis that the designed GA-BF tuning PID controller is robust in its operation for its effectiveness in solving certain difficult real world optimization problems. In this work we will present the Genetics Algorithm and Bacteria Foraging Optimization Algorithm as a novel algorithm using the social foraging behavior for Escherichia coli bacteria to make tuning for PID parameters for an experimental plant system. Comparing with Conventional Algorithm, this proposed algorithm was more efficient in improving the step response characteristic for this system. Also, these controllers have a simple architecture and the potentiality of implementation in real time environment.

\section{ACKNOWLEDGMENT}

Authors acknowledge the support, encouragement and facilities provided by the School of Electrical Engineering and management of VIT University, Vellore, Tamilnadu, India in carryout the presented research work. And also thank the IIT Bombay, Department of Energy Science and Engineering for provided the solar kit.

\section{REFERENCES}

[1] Chetan Singh Solanki "Solar Photovoltaics- Fundamentals, Technologies and Applications", Second Edition (a)2011 by PHI Learning Private Limited, New Delhi.

[2] Sobhan Dorahaki , "A Survey on Maximum Power Point Tracking Methods in Photovoltaic Power Systems", Bulletin of Electrical Engineering and Informatics Vol. 4, No. 3, September 2015, pp. 169 175 ISSN: 2089-3191.

[3] Melanie Mitchell “An Introduction to Genetic Algorithms", Fifth printing, 1999, Massachusetts Institute of Technology.

[4] Randy L.Haupt, Sue Ellen Haupt "Practical Genetic Algorithms", Second Edition A John Wiley \& Sons, Inc., Publication,2004.

[5] Filho.E.R Gazoliand.J and Villalva.M.G, "Comprehensive approach to modeling and simulation of photovoltaic arrays", IEEE Transactions on Power Electronics, Vol 24, May 2009.

[6] M. Fortunato, A. Giustiniani, G. Petrone, G. Spagnuolo, and M. Vitelli,"Maximum power point zracking in a onecycle-controlled single-stage photovoltaic inverter," IEEE Trans. Ind. Electron, vol. 55, no. 7, pp. 2684-2693, Jul. 2008 . 
[7] S. Yuvarajan, Dachun Yu, Shanguang Xu, "A novel power converter for photovoltaic applications", Journal of Power Sources, Elsevier Science, Vol. 135, pp. 327-331, 2004. pp. 440-449, Mar. 2006.

[8] Gomathi C, Navya Nagath, Veerakumar, "Sampled Reference Frame Algorithm Based on Space Vector Pulse Width Modulation for Five Level Cascaded H-Bridge Inverter", Buletin Teknik Elektro dan Informatika (Bulletin of Electrical Engineering and Informatics) Vol. 3, No. 2, June 2014, pp. 127 140 ISSN: 2089-3191.

[9] S.Mallika, R.Saravanakumar, “ Design and Impementation of a Buck-Boost Converter using Lag Lead Compensator”, - International Conference on Renewable Energy Technologies- Icoret 2011, PSG College of Technology, Coimbatore.

[10] S.Mallika, R.Saravanakumar, "Review on Ultracapacitor- Battery Interface for Energy Management System", International Journal of Engineering \& Technology, ISSN: 0975-4024, Vol.3 (1), 2011, 37 - 43.

[11] M. Fortunato, A. Giustiniani, G. Petrone, G. Spagnuolo, and M. Vitelli,"Maximum power point tracking in a onecycle-controlled single-stage photovoltaic inverter," IEEE Trans. Ind. Electron, vol. 55, no. 7, pp. 2684-2693, Jul. 2008.

[12] Dong Hwa Kim, Ajith Abraham, Jae Hoon Cho "A hybrid genetic algorithm and bacterial foraging approach for global optimization”- Science Direct Information Sciences 177 (2007) 3918-3937.

[13] A.Varsek, T. Urbacic and B. Filipic, Genetic Algorithms in Controller Design and Tuning, IEEE Trans. Sys.Man and Cyber, Vol. 23, No. 5, pp1330-1339, 1993.

[14] Grefenstette, Optimization of control parameters for geneticalgorithms. IEEE Trans on SMC, 1986, 16(1):122-128.

[15] Varsek A, Urbancic T, Filipic B. Genetic algorithms in controller design and tuning. IEEE Trans Systems, Man and Cybernetics, 1993, 23(5): 1330-1339.

[16] Dong Hwa Kim, and Jae Hoon Cho "Robust Tuning of PID Controller Using Bacterial-Foraging-Based Optimization”- Journal of Advanced Computational Intelligence and Intelligent Informatics, Vol.9 No.6, 2005. 